\title{
(t)
}

\section{EL DEBATE PARA SUPERAR LA CRISIS CAPITALISTA ACTUAL}

The debate on overcoming the current capitalist crisis

\author{
Julio C. Gambina'
}

\section{RESUMEN}

El texto discute sobre las distintas opciones de superación de la crisis, según sea el diagnóstico que se asume. Para quienes creen que puede sustentarse la continuidad del capitalismo mundial se habilita una discusión entre una mayoría neo desarrollista y una minoría que propugna las recetas tradicionales del ideario neoliberal construido en las últimas décadas. La primera corriente propugna una vuelta al Estado, transitoriamente en algunos casos, para el salvataje de empresas en problemas y reanimar la actividad económica y restablecer el régimen del capital. La segunda insiste con las dinámicas liberalizadoras, base del pensamiento hegemónico de las últimas décadas, especialmente sustentada en los organismos internacionales. Ambos defienden la potencial continuidad del capitalismo contemporáneo. Otra versión se sostiene desde la crítica al capitalismo y promueve un ideario y práctica anti capitalista. En esta variante se analiza la experiencia latinoamericana, especialmente de la primera década del Siglo XXI, rica en propuestas y sugerencias que van desde la práctica de la integración alternativa, caso de la Alternativa Bolivariana para las Américas (ALBA);

' Doctor en Ciencias Sociales (UBA). Profesor titular de Economía Política (UNR). Presidente de la Fundación de Investigaciones Sociales y Políticas (FISYP). Miembro del Comité Directivo del Consejo Latinoamericano de Ciencias Sociales (CLACSO). E-mail: <jcgambina@gmail.com>. 
la nueva arquitectura financiera para la región, lo que supone la constitución del Banco del Sur, el uso compartido de reservas internacionales y la promoción del comercio regional con utilización de monedas locales, en la perspectiva de una moneda común. La discusión incluye el análisis de los sujetos en pugna; sean las transnacionales articuladas con sus respectivos Estados nacionales y los organismos internacionales, los que ensayan formas de sujeción y disputa del consenso global, tal como ocurre con el G20; o las respuestas que emanan de la organicidad popular para pensar una realidad transformada desde el anti capitalismo.

\section{PALABRAS-CLAVE}

Crisis.Dominación. Anti capitalismo.

\section{ABSTRACT}

This paper discusses the several options to overcome this crisis according to the diagnosis made. For those who think global capitalism can be sustained, the study offers a discussion between a neo-developmentalist majority and a minority proposing traditional recipes of neoliberal ideology developed in the past decades. The first current calls for a return to the State - temporarily in some cases - to salvage troubled companies and thus revive economic activity and restore the rule of capital. The second current insists on a liberalization dynamics - the basis of hegemonic thinking in the past decades -, mainly supported by international agencies. Both advocate the potential continuity of contemporary capitalism. Another version is supported by the critique of capitalism, promoting anti-capitalist ideology and practice. This latter version analyzes the Latin American experience, especially in the early 21st century. It is rich in proposals and suggestions that range from the practice of integrating alternative - the case of Bolivarian Alternative for the Americas (ALBA); to the new financial architecture for the area, which includes setting up the South Bank, sharing international reserves and promoting local trade using local currencies, with the prospect of a common currency. The discussion includes analyses of the matter in question: the interaction between transnational companies and their respective national governments and interna- 
tional agencies, which tested ways to support and dispute global consensus such as $\mathrm{G}_{20}$; and the responses deriving from popular organicity to think about a reality transformed by anti-capitalism.

\section{KEYWORDS}

Crisis. Domination. Anti-capitalism.

\section{INTRODUCCIÓN}

Nos proponemos relevar las diferentes propuestas que actúan en el debate regional como salidas de la crisis. Éstas se propugnan de acuerdo al diagnóstico político que se hace de la situación. Por lo tanto según las evaluaciones que se hagan, de acuerdo a si atravesamos una crisis en o del capitalismo serán cada una de las propuestas para superarla.

Si nos remontamos en la historia, observamos que la pregunta ¿qué hacer ante la crisis capitalista? fue contestada en otras ocasiones y desde distintos ángulos. Desde una praxis revolucionaria se desafiaba con la revolución socialista que había adquirido, en Rusia de 1917, carta de ciudadanía, impulsando en años sucesivos procesos revolucionarios en Europa y animando tempranamente a José Carlos Mariátegui a formular el mito de la revolución socialista para América Latina (MARIÁTEGUI, 1982)2 . Desde otro ángulo y ante la crisis del $30^{\prime}$, hemos visto que sectores de las clases dominantes impulsaron reestructuraciones de políticas económicas y variaciones de las relaciones sociales de producción y distribución para asegurar la continuidad de la acumulación de capitales y la dominación del régimen capital. El objetivo apuntaba a recomponer la capacidad de generar plusvalor y acumular riqueza y poder para las clases dominantes.

\footnotetext{
${ }^{2}$ Mariátegui (1982). Menciones especiales en 7 ensayos de interpretación de la realidad peruana (Tomo I) y Punto de vista antiimperialista (Tomo II). En el editorial del número 17 de Amauta titulado Aniversario y balance Mariátegui señala que "La revolución latinoamericana, será nada más y nada menos que una etapa, una fase de la revolución mundial. Será, simple y puramente, la revolución socialista." (Tomo I).
} 
Pero también puede verificarse la simultaneidad de las estrategias que ambas perspectivas desplegaron para darle un curso al desarrollo social ante la crisis de fines de los 60' y comienzos de los 70' del Siglo XX. Por un lado, la Revolución Cubana simboliza en la región la opción de cambio sistémico que puso en pie múltiples procesos de transformación (vía armada y/o de lucha electoral), los que son coherentes con otros en el ámbito mundial (el mayo francés, la primavera de Praga, la denuncia de la invasión a Viet Nam entre las más destacadas entre 1968 y 1973). Por el otro lado se verifican iniciativas como el Foro Económico Mundial reunido en Davos en 1971 y su saga hasta el presente; la crisis monetaria desatada con la inconvertibilidad del dólar en agosto de 1971 y especialmente los ensayos de política neoliberal aplicados por los monetaristas ortodoxos de las dictaduras militares del Cono Sur de América. Ensayos que se generalizaron por todo el planeta desde la consolidación hegemónica de esa corriente con la asunción al gobierno de Margaret Thatcher y Ronald Reagan en 1979 y 1980 respectivamente.

La respuesta neoliberal fue en confrontación tanto con la estrategia revolucionaria como con la visión keynesiana de la organización económica de la sociedad desde fines de la segunda guerra mundial. Así, se constituyó en propuesta hegemónica hasta la presente crisis. La discusión actual se centra en cómo actuar para superar la crisis del capitalismo realmente existente tras décadas de hegemonía neoliberal y ortodoxia monetarista. El debate contiene las variantes ideológicas y políticas de quienes pretenden relanzar el capitalismo en su versión más monetarista y neoliberal, por medio del keynesianismo militar; aquellos que propugnan otro capitalismo posible, basado en una concepción neo desarrollista; y quienes finalmente apuestan a la construcción de un orden alternativo, anticapitalista y por el socialismo.

\section{EL KEYNESIANISMO MILITAR}

Una salida posible de la crisis desde EEUU es la reiteración del camino asumido para superar la anterior recesión del año 2001, donde se combinó keynesianismo militar (estrategia contra el terrorismo) con endeudamiento público y privado. De hecho, el carácter desen- 
frenado de la adquisición de obligaciones desembocó en la burbuja inmobiliaria, y la crisis de las hipotecas (2007), eclosión inicial de la crisis actual. Claro que no puede repetirse la historia del mismo modo, porque la ofensiva militarista aparece atrapada en Irak y Afganistán, sin clara salida, dado que esa maniobra pierde legitimidad a nivel mundial y al interior de Estados Unidos, acrecentando a la vez un déficit fiscal cada vez más difícil de financiar, así la militarización puede transitar otros caminos. Lo que no se puede es estimular el crédito de un sistema bancario con mora creciente y escasa propensión de la población a endeudarse ante la debacle financiera en curso, máxime cuando EEUU asume una deuda pública que supera los 11 billones de dólares. Ni la baja de la tasa de interés actúa para favorecer un crédito del que huyen probables deudores ante la cruda realidad de la recesión y la inflación. La estrategia utilizada en el 2001 exacerbó los problemas estructurales de déficit fiscal, comercial y endeudamiento público y privado de EEUU. Son límites objetivos que impiden reiterar ese camino, especialmente cuando se piensa en la continuidad y profundidad de la crisis.

La innovación - si así puede llamarse- ante el fracaso de que el capital privado sostenga a las entidades en crisis, es que se acude al sempiterno regreso de la intervención estatal bajo nuevas formas, con aportes del Tesoro y fondos públicos para sostener a las entidades financieras y empresariales en decadencia. El objetivo es que la rueda de la circulación productiva y mercantil vuelva a funcionar para relanzar el régimen del capital bajo una nueva ofensiva de la liberalización global. Se trata de intervenir desde la cúpula del poder estatal aunque solo sea temporalmente, para estabilizar la situación económica y retomar la ofensiva por la liberalización.

El orden mundial resultante de este proceso encuentra a EEUU en un papel hegemónico en el sistema mundial, más allá de las visibles disputas existentes. Es el resultado de su peso económico y militar, pero también ideológico cultural. El peso económico remite al papel de las Corporaciones transnacionales de origen estadounidense, sí, pero también a la capacidad del Estado de EEUU para fijar políticas globales. Luego de la recesión de EEUU en el 2001, en base a un paquete de medidas fiscales se produjo un proceso de recuperación que implicó una tendencia al aumento de las tasas de interés por 
parte de la Reserva Federal. Con estas medidas se definió también la situación de los mercados de valores del mundo, sea cual sea la importancia y el volumen que cada uno de ellos administra. La crisis financiera surgida a mediados de 2007, trae consigo una tendencia a la baja de las tasas de interés, la cual impacta en el sistema financiero y económico global. Apuntamos a considerar que las subas o bajas de tasas de interés, motivado por necesidades internas de la economía estadounidense afectan al sistema mundial en su conjunto. Es dialéctica la relación entre poder económico y poder militar. El dólar sostiene a los misiles y éstos sostienen al dólar.

Así, la invasión militar en medio oriente tiene fines económicos y se materializa militarmente, pero en forma simultánea se busca, a nivel ideológico, lograr un consenso global sobre una política de interés particular. Se pretende naturalizar globalmente el modus operandi y ello supone un accionar ideológico cultural. Quizá por ello, el mayor logro de la potencia hegemónica sea de tipo cultural. Al menos en parte, por ese intermedio llegó a obtener un importante aval respecto de su accionar imperialista; es decir ha ganado el sentido común de la población mundial para esa estrategia.

La crisis no amedrenta la ofensiva del capital, que a través de su asociación con el Estado más poderoso de la tierra, cristaliza su iniciativa política para subordinar las relaciones económicas y asegurar la valorización del capital, aún a costa de nuevas y sucesivas crisis. En ese marco se viene desarrollando una institucionalidad del nuevo orden. Entre otros se destaca la aparición del G7, G8 y el propio $\mathrm{G}_{20} \mathrm{O}^{3}$, como intentos de gobierno mundial.

Si alguna vez Carlos Marx aludió al paso de la subsunción formal a la real del trabajo en el capital, ante la crisis de los 70' el capital impulsó una fuerte iniciativa política para restablecer el ciclo económico y asegurar las condiciones de reproducción de la acumulación de valor y del sistema de dominación en escala global, aunque siga teniendo, claro está, forma nacional de expresión. Actualmente

${ }^{3}$ El Grupo de los 7 está formado por EEUU, Canadá, Gran Bretaña, Francia, Alemania, Italia y Japón. El Grupo de los 8 es el G7 más Rusia. Por último, al Grupo de los 20 lo integran los miembros del G8 más Arabia Saudita, Argentina, Australia, Brasil, China, India, Indonesia, México, República de Corea, Sudáfrica, Turquía y la Unión Europea, aunque representados por esta, son invitados también España y Holanda. 
una de las alternativas que se manejan para relanzar la ofensiva del capital en este escenario de crisis, es la intensificación de la violencia imperialista y el terrorismo de Estado por parte del Estado hegemónico. Esto es: liberalizar las relaciones económicas y sociales a costa de vidas humanas.

\section{LA ILUSIÓN NEO DESARROLLISTA COMO POSIBLE SOLUCIÓN}

Desde la perspectiva de la transnacionalización del capital y la nueva división internacional del trabajo, algunos gobiernos perciben esta crisis como una oportunidad para mejorar su posicionamiento en esa macro estructura económica, dado su carácter de voceros y expresión del capital local. De hecho esta visión no es nueva, sino que ya en los años 50' y 60' se consideraba que era factible el paso del subdesarrollo al desarrollo. Solo era necesario seguir la receta transitada por los países desarrollados y así se lograría el objetivo tan anhelado. Sin embargo se olvidaba o negaba la dialéctica entre desarrollo y subdesarrollo; entre dominantes y dominados; entre revolución industrial producto de una acumulación que incluía el despojo de las riquezas naturales del territorio de nuestra América y el asesinato de poblaciones explotadas en la extracción de mineral. En definitiva, de una acumulación originaria del capital sustentada sobre el despojo de poblaciones enteras.

La historia vuelve a repetirse para generar nuevas acumulaciones. Existen estrategas de nuestra región que imaginan una inserción renovada de países de menor desarrollo en la cumbre del poder capitalista. Parten de la hipótesis de una crisis en el centro que no afecta, esencialmente, a la periferia. Es un diagnóstico erróneo que sigue pensando en términos de economía y política entre naciones, internacional, sin dimensionar el carácter mundial del capitalismo. Esta visión está sustentada en la ilusión que genera la macroeconomía estable y en crecimiento de los últimos años para la región latinoamericana.

La realidad de equilibrios fiscales y comerciales en la coyuntura, tanto como aceitadas políticas monetarias y cambiarias con sólidas tenencias de reservas internacionales hacen aparecer consistentes 
las condiciones de los países ante la crisis presentada en el norte desarrollado. Habría que recordar que el ciclo de ascenso de la región es posterior a una década de reestructuraciones regresivas ocurridas en los 90'. Década que no estuvo exenta de los episodios de crisis ya mencionados entre los que se cuentan los acaecidos en México 94', Brasil 98', Argentina 01'; todos ellos de fuerte impacto en los sectores sociales de menores ingresos. La crisis se anticipó en nuestra región y la proyección prolongada de la crisis en el norte se descarga sobre nuestros países, tal como se aprecia en los indicadores socioeconómicos abordados en el acápite anterior.

Los datos fehacientes hacen caer en la realidad a aquellos gobernantes o académicos que imaginaban blindadas economías de nuestros países, producto del ciclo de ascenso de la producción, el empleo, las ganancias y los salarios (aunque éstos satisfagan cada vez menos los requerimientos de una calidad de vida digna). El problema es la ilusión neo desarrollista instalada con pretensión hegemónica de corrientes críticas a los neoliberales. Estos impusieron su credo mercantil por cuatro décadas en gobiernos y en la academia, siendo la crisis actual la que desnuda los límites de la teoría y política económica liberalizadora.

Es un hecho que los gurúes neoliberales y sus epígonos en la esfera política ya no opinan a viva voz. Entre tanto se resguardan tras la prudencia de aquellos que estimulan nacionalizaciones transitorias; intervenciones estatales mientras se justifique, para luego reanudar una ofensiva de mercantilización profunda de las relaciones sociales económicas. Esa es la impronta del neo keynesianismo.

Debemos insistir que el keynesianismo existió sobre la base de la ofensiva de una subjetividad revolucionaria que discutía el orden capitalista vigente a comienzos del siglo XX. También señalar que el keynesianismo se construyó en el marco de una época de guerras mundiales (1914/1918 y 1939/1945) con destrucción inmensa de fuerzas productivas, para instalarse y propagarse en el ciclo de oro de 1945 a 1975 sobre la base del poder hegemónico de Estados Unidos.

Ahora bien, actualmente y ante la ausencia de una subjetividad revolucionaria en ascenso, la crisis condiciona al pensamiento hegemónico de los últimos años y posterga sus objetivos liberalizado- 
res hasta mejores momentos. Esta situación hace pensar que se pueden recrear circunstancias para restablecer políticas del ciclo keynesiano. De hecho, un dato de la realidad es la creciente intervención de un Estado capitalista que en rigor, nunca había dejado de sustentar el programa de liberalización demandado por el gran capital. Queremos reparar en el comportamiento de los capitales en particular que a pesar de la crisis acumulan ganancias, riqueza y poder y pujan por darle continuidad a la liberalización. Vale en ese sentido recoger las resoluciones de las cumbres mundiales convocando a la reanudación de la ronda de Doha de la Organización Mundial de Comercio. Es que aquellos capitales precisan desplegar su accionar en pos de la apropiación de los recursos naturales sin ningún tipo de limitación, afirmando con ello la libre circulación de capitales. En síntesis, el hecho de que los más conocidos gurúes del neoliberalismo se llamen a silencio no hace desaparecer el objetivo liberalizador de los capitales a escala mundial.

Los pronósticos sobre la crisis son diversos, desde aquellos que imaginaron una recesión corta en el 2007, hasta quienes anunciaron la prolongación del estancamiento por varios años. En esas condiciones la puja política para incidir sobre las decisiones de los Estados capitalistas es gigantesca, tal como viene ocurriendo con los millonarios fondos de salvataje destinados por los principales países capitalistas. Aludimos a la dimensión política puesta en juego en la crisis, que involucra el poder del capital y las ilusiones sobre su contención.

Por todo ello es fundamental la discusión del diagnóstico sobre la crisis y su caracterización. Si el problema es la regulación (de las finanzas especialmente) entonces el tema se resuelve regulando, que parece ser la salida que se encuentra en los principales cónclaves oficiales desde la emergencia de la crisis. Es una perspectiva similar a quienes visualizan excesos empresariales o de las cúpulas gerenciales en su apropiación de recursos, para lo cual la solución pasa por restringir la asignación de grandes sumas de ganancias, de honorarios y premios para las cúpulas empresariales o gerenciales. ¿Es posible regular la dominación monopolista de las transnacionales en tiempos de revolución de las comunicaciones? Las normas de Basilea prefiguran tanto el fracaso de los intentos reguladores 
en el sistema financiero mundial, como también el de intentar establecer códigos de conducta a las transnacionales en el sistema de Naciones Unidas. La agresión del capital en la explotación de los trabajadores y sobre los recursos naturales para satisfacer sus objetivos ponen de manifiesto que no sólo se trata de una crisis económica, sino de una crisis sistémica y que la respuesta del capital, más allá de ciertas nacionalizaciones propuestas desde el Estado capitalista, se orienta a la generación de condiciones económicas y políticas para hacer avanzar el sistema capitalista, con independencia del costo social y natural que ello conlleve.

El Nobel de economía 2008 señaló: “[...] cuando leo los comentarios recientes sobre política financiera de altos funcionarios de Obama, me siento en el túnel del tiempo, como si estuviéramos todavía en 2005, Allan Greenspan fuera el Maestro y los banqueros, los héroes del capitalismo" (KRUGMAN, 2009). El mismo analista rescata comentarios del secretario del Tesoro estadounidense, Timothy Geithner quien afirma: "( $T$ )enemos un sistema financiero que es dirigido por accionistas privados y manejado por entidades privadas y nos gustaría hacer todo lo posible por conservar ese sistema", mientras se apresta a meter en problemas a los contribuyentes por las pérdidas enormes de ese sistema (KRUGMAN, 2009). Por su parte el diario Washington Post afirma que Geithner y Lawrence Summer, el principal asesor económico de Obama, “[... ] piensan que los Estados son malos como gerentes de bancos", en oposición seguramente a los genios del sector privado que se las ingeniaron para perder más de un billón de dólares en apenas unos años" (KRUGMAN, 2009). Paul Krugman exige avanzar en el camino de las nacionalizaciones, aunque en forma temporal para luego volver a privatizar. En otro sentido, pero también dentro del sistema capitalista, Jeffrey Sachs (2009) sugiere que

(U)no de los históricos aportes del presidente Barack Obama será un impresionante acto de malabarismo político: convertir la abrumadora crisis económica en el lanzamiento de una nueva era de desarrollo sostenible. Su paquete de estímulo macroeconómico podría o no amortiguar la recesión y sin duda se avecinan encarnizadas batallas partidarias por las prioridades. Pero Obama ya está fijando un nuevo derrotero histórico al reorientar la economía del consumo 
privado hacia las inversiones públicas dirigidas a los grandes desafíos de la energía, el clima, la producción de alimentos, el agua y la biodiversidad. (Agrega que) lo que está tomando forma es nada menos que un modelo de capitalismo para el siglo XXI, comprometido con el doble objetivo del desarrollo económico y la sostenibilidad (SACHS, 2009).

Por ello sugiere la reestructuración de la industria automotriz y abandonar el paradigma productivo sustentado en el petróleo por nuevas tecnologías de la energía. Resulta grave disimular los peligros de la crisis, tanto como insistir en las recetas que derivaron en sucesivas crisis desde la restauración conservadora. Es por ello necesario pensar en términos de alternativas al orden financiero y económico para proponer otro ordenamiento del sistema mundial.

\section{ALTERNATIVA Y OTRO MUNDO POSIBLE}

A las propuestas de salidas referidas al keynesianismo militar y al neo desarrollismo se opone una tercera, que puede ser caracterizada como una perspectiva emancipadora. Es que al tiempo que se presenta la ofensiva del capital para su programa liberalizador, se desarrolla un proceso creciente de crítica y resistencia que habilita a pensar en términos de alternativa.

No se trata de una utopía o fantasía, especialmente en América Latina, con procesos de masas que en los últimos veinte años hicieron frente a las políticas hegemónicas neoliberales. Se trata de una dinámica social movilizada que pretende construir otras relaciones que rijan la economía, la política y la sociedad. Son dos décadas iniciadas con el histórico Caracazo (febrero de 1989) que da origen a lo que hoy denominamos revolución bolivariana; o de condensación de las luchas de los pueblos originarios en torno a los más de cinco siglos de dominación y que sustentan los actuales procesos de cambio político en Bolivia o Ecuador; pero también de despliegue de una acumulación de lucha de los trabajadores organizados de Brasil, Uruguay y Argentina para generar primero criticas y luego alternativas a la hegemonía neoliberal de los años 90'. Es el camino construido en ese tiempo en Paraguay, Nicaragua o 
El Salvador. Cada quién desde su especificidad, pero todos en una perspectiva de cambio nacional y búsqueda, a ritmo diferenciado, de procesos integradores innovadores. La mayoría de estos países mencionados se posicionaron en 2005 (IV Cumbre de Presidentes de las Américas, Mar del Plata, Argentina), en confrontación contra la estrategia imperialista de integración subordinada al programa liberalizador de los tratados comerciales, cuya máxima apuesta fue el Área de Libre Comercio para las Américas (ALCA).

La existencia de una dinámica alternativa que se procesa especialmente en América Latina y el Caribe se puso de manifiesto en las dificultades que encontró Estados Unidos en la $V^{\circ}$ Cumbre de Presidentes americanos realizada en Trinidad y Tobago entre el 17 y 19 de abril de 2009. Allí, más allá del temario previsto, el eje de las discusiones se concentró en el bloqueo estadounidense sobre la isla de Cuba y la expulsión cubana de la Organización de Estados Americanos (OEA) en 1962. A los pocos días el tema volvió a tomar cuerpo en la reunión de este organismo y en un hecho histórico se suspendió la exclusión de Cuba de la OEA. El tema es importante más allá del nulo interés cubano por reinstalarse en un ámbito que considera inútil para los intereses propios y regionales, precisamente por la incapacidad que tiene EEUU por diseñar la agenda en debate en la coyuntura.

En síntesis el presente se caracteriza por la discusión sobre la crisis, pero ya no sólo en cómo relanzar el ciclo del capital, sino en pensar en la materialización de otras relaciones sociales más justas para otro mundo posible.

\section{POLÍTICAS ANTI CRISIS: ACTORES Y PERSPECTIVAS}

Expuesto el abanico de posibles horizontes para salir de la crisis, nos proponemos ahora indagar acerca de las políticas que efectivamente se están llevando a cabo en pos de paliar sus efectos. En ese sentido, cabe recordar que, si bien la eclosión inicial tiene causas de índole financieras y especulativas, la realidad es que hoy en día existe una multiplicidad de frentes críticos entre los que se cuentan la crisis climática, productiva, social, ambiental. Del carácter global 
de la crisis se infiere que no resulta ni plausible ni efectiva una solución focalizada. Es preciso un cambio rotundo que tenga como eje el modo de producción capitalista.

En ese sentido afirmamos que si bien es imperioso reconocer la estrategia global del capital es preciso favorecer una visión conjunta, teniendo en cuenta también las acciones de resistencia y alternativa desarrolladas. Se trata entonces de dejar de lado la fragmentación del conocimiento y de la realidad, tan funcional al actual modelo de acumulación. Por lo tanto, intentaremos aquí determinar cuáles son los actores y las estrategias históricas y coyunturales que se ponen en juego en este contexto de crisis global

\section{ESTADO Y MERCADO COMO RELACIÓN SOCIAL}

Venimos sosteniendo que en pos de ordenar las relaciones sociales de explotación a nivel mundial, el capital transnacional plantea una estrategia de saqueo, explotación y violencia. Para ello precisa de la colaboración de los Estados nacionales, dado que con su accionar aseguran que el acontecer cotidiano siga el curso sugerido. Nada de lo que ocurre en las relaciones entre capitalistas y trabajadores sucede sin el accionar concreto de los Estados. Es una afirmación válida en las mutaciones de las relaciones en el ámbito de las empresas, como en el conjunto social. Sin el Estado y sus medios represivos no puede entenderse el disciplinamiento del movimiento de trabajadores en cada uno de los países y en escala global, más allá de resistencias particulares, parciales conquistas y reconquistas de determinados trabajadores en alguna parte del planeta. Pero también debe consignarse el accionar propagandístico e ideológico de los Estados para hacer normal las demandas del capital en el conjunto de la sociedad. Las formas de la violencia no remiten sólo al uso de las armas y la represión física, sino que también se acude a la violencia moral del chantaje y la manipulación de la conciencia social para naturalizar el orden vigente y las nuevas formas que asume la explotación.

Contrario a lo que algunos sostienen, actualmente no hay menos Estado, sino que ocurre un cambio de funciones de los Estados 
nacionales. De este modo, no resulta adecuado contraponer el mercado al Estado como tendencias contrarias. Ambas categorías, mercado y Estado, son conceptos relacionales, implican relaciones sociales y como tales son contradictorias y expresan determinados intereses de clase en el capitalismo. Es que es el propio Estado el que propone y conduce la mercantilización capitalista de la sociedad. Sólo entre paréntesis vale decir que es necesario estudiar la proposición del Estado en China, orientado a mercantilizar el socialismo, lo que requiere un debate político y teórico que escapa nuestras motivaciones en estas reflexiones. El Estado resulta imprescindible para canalizar con éxito la ofensiva global del capital. En efecto, son los Estados los que están dando nueva forma al orden mundial pretendido. Desde la Constitución europea, que incluye por cierto su capítulo económico liberalizador, al ALCA o cualquier tratado comercial y de inversiones, es negociado por los Estados. Son los Estados los que disputan entre sí la radicación de inversiones de capital y no dudan para ello de otorgar todas las facilidades demandadas para su atracción, tanto fiscales, monetarias, crediticias, como reformas regresivas del régimen laboral.

Existe, además, un entramado articulado de viejas y nuevas organizaciones globales, desde los Organismos financieros internacionales y el sistema general de Naciones Unidas, a la Organización Mundial de Comercio (OMC) y múltiples tratados bi y multilaterales que negocian los Estados para abrirle espacio a las demandas de reestructuración regresiva del orden global planteadas por el capital. Es decir, los sujetos de las transformaciones capitalistas en curso, los capitales, en su fase transnacional recurren a los Estados nacionales para modelar a su demanda específica el orden social global. Es curioso, pero en la época de la transnacionalización del capital, éste sigue recurriendo a formas nacionales de empujar su estrategia, y en ese lugar encuentra nueva función para el Estado Nación. Si éste fue fundamental para consolidar la acumulación originaria del capital en cada país, hoy es necesario para asegurar una expansión internacional de esos capitales en un contexto de crisis. La lucha entre los capitales se presenta en el mercado y cuenta con ayuda del poder del Estado Nación del país de origen de cada capital, que pretende disciplinar la ley del valor. No es un tema nuevo, pues lo reconocemos desde la existencia del imperialismo, donde 
la ley del valor se abría camino favoreciendo la ganancia de monopolio. Ya no se trata de la libre competencia, sino de la existencia dominante del monopolio que impone condiciones y precios, y que por ello se apropia de una cuota mayor de plusvalía que la generada en su seno, incluso por encima de la ganancia media. El Estado es clave en el sostén de la estrategia de acumulación de los capitales.

La tendencia a la transnacionalización del capital mantiene, en territorios nacionales, su ámbito de impulso y de toma de decisiones. Es desde los Estados Nación que se continúa ejerciendo el imperialismo. Polemizamos por tanto con las concepciones que aluden al imperio como una nueva forma de ejercicio de la dominación del capital. Existe por tanto un doble desafío de una contestación a la transnacionalización en una resistencia sin fronteras, y al mismo tiempo la continuidad de luchas nacionales contra el capital, los propios Estados e incluso a la discusión y lucha interestatal para afirmar procesos de liberación social y nacional.

\section{LOS ESTADOS Y SU ARTICULACIÓN GLOBAL: EL CASO DEL G20}

De las guerras mundiales del siglo XX, crisis del 30' mediante, emergió un orden mundial bipolar que entró en crisis a comienzos de los años 70'. Recordemos que el gobierno estadounidense declaró la inconvertibilidad del dólar en 1971 y con ello rompió unilateralmente los acuerdos monetarios de Bretton Woods. A partir de ese momento, y para ocuparse del orden mundial en crisis, surge, desde la perspectiva capitalista, el selecto Grupo de los 7 - conformado por Estados Unidos, Canadá, Alemania, Inglaterra, Francia, Italia y Japón- como conjunto ordenador del sistema financiero y económico mundial. Con el derrumbe de la Unión de Repúblicas Socialistas Soviéticas (URSS) y el fin de la bipolaridad, se incorpora Rusia al ahora Grupo de los 8, (G7 más Rusia).

Por su parte, el $\mathrm{G}_{2} \mathrm{O}^{4}$ es producto de la crisis, se creó en el año 1999, a fin de discutir las secuelas de las crisis, mexicana, asiática

${ }^{4}$ Recordemos que el G20 está integrado por los siguientes países: EEUU, Canadá, Alemania, Inglaterra, Francia, Italia, Japón, URSS, Arabia Saudita , Argentina, Australia, Brasil, China, India, Indonesia, México, República de Corea, Sudáfrica, Turquía y la Unión Europea. 
y brasileña, las que azotaron al globo durante la última década del siglo pasado. Es decir que este conclave emerge como consecuencia de la generalización de las crisis. ¿Por qué lo afirmamos? Es que originariamente, el G20 era un cónclave ministerial, es decir, una reunión de los ministros de hacienda y finanzas de los países miembros que se convocaba bianualmente. Sin embargo esta situación viró con el derrumbe de Lehman Brothers -entidad emblemática de la especulación financiera contemporánea - en septiembre de 2008. Entonces, la Unión Europea solicitará al gobierno de George W. Bush que cite al G20, ahora como cumbres presidenciales, convocando a los primeros ministros de los estados miembros en noviembre de 2008.

Queda claro que el Grupo de los veinte, como lo conocemos hoy, es producto de la insostenible situación económica y financiera que provoca la bancarrota de importantes y diversas entidades financieras. Emerge para restaurar las condiciones de acumulación capitalistas en un contexto global de debacle económica.

Desde el año 2008 a la actualidad el G20 se constituyó en Cumbres presidenciales y entre cada reunión, funciona en cuatro grupos de trabajo , a saber: el correspondiente a la regulación y trasparencia; otro encargado del área de cooperación internacional e integridad del mercado financiero; aquel que trabaja en pos de generar reformas en el Fondo Monetario Internacional; y por último el grupo de trabajo ${ }^{5}$ que se avoca a las cuestiones inherentes al Banco Mundial y otros bancos multilaterales de desarrollo.

En términos generales, las propuestas del G20 apuntan centralmente a mantener políticas anticíclicas para salvar a las corporaciones trasnacionales financieras e industriales, es decir, continuar relegando la cuestión social. Al mismo tiempo se orientan a fortalecer el Fondo Monetario Internacional y el Banco Mundial sin modificar - ni que hablar de cuestionar - sus roles. En síntesis el cónclave de los 20 países industrializados y emergentes pretende mantener y fortalecer la arquitectura financiera mundial regresiva vigente, ratificando el rumbo por la liberalización y avalando las conclusiones de la Ronda de Doha. De ahí se entiende que suscriban un acuerdo que reza:

5 Información extraída del sitio de internet oficial del cónclave disponible en: <www.g20.org>. 
[... ] mantenemos la apertura, la libertad de los mercados y reafirmamos los compromisos tomados en Washington y en Londres: nos abstendremos de elevar obstáculos a las inversiones o a los intercambios de bienes y de servicios o de imponerlo de nuevo, (en fin) lucharemos contra el proteccionismo (LEADERS'..., 2009).

Los Estados que conforman el G20 confían entonces en la rehabilitación del sistema financiero y en la autorregulación de los mercados, base de la ideología neoliberal. En ese sentido, están convencidos que:

(E)stamos construyendo un sistema financiero más resistente que sirva a los intereses de nuestras economías, reduzca el riesgo moral, limite la acumulación de riesgo sistémico y apoye un crecimiento fuerte y estable. Hemos fortalecido el sistema financiero al reforzar la supervisión prudencial, mejorar la gestión del riesgo promover la transparencia reforzar la cooperación internacional. Hemos alcanzado mucho [...] Pero hay más trabajo por hacer [...] (THE G-20 TORONTO..., 2010). ${ }^{6}$

Paralelamente, es preciso señalar que en 2009 el G20 permitió la ampliación de la capacidad de préstamos del FMI a 750.00 millones de dólares. De los cuales Brasil aportó 10.000 millones de dólares y China otros 50.000 millones. Asimismo autorizó el incremento de los Derechos Especiales de Giro (DEG) a 250.000 millones de dólares. Los DEG se integran a las reservas internacionales de cada país en función de la cuota en el FMI. Todos ellos constituyen mecanismos para inyectar liquidez a fin de favorecer la sustentabilidad de los pagos de deuda y evitar mayores impactos financieros de la crisis en la economía mundial.

Así, coincidimos con la red global ATTAC quien afirma que este grupo de países pretende "[...] tan sólo salvaguardar las herramientas financieras globales controladas por organismos fracasados y tremendamente deslegitimados por los pueblos, en especial los del Sur" (MARTINEZ GARCIA, 2009) . También el G20 anuncia la

\footnotetext{
${ }^{6}$ Declaración final de la Cumbre de Toronto del G20 (THE G-20 TORONTO..., 2010).

${ }^{7}$ Comunicado de la Asociación por un Tributo a las Transacciones financieras y de Ayuda al Ciudadano España (MARTINEZ GARCIA, 2009).
} 
“[... ] retirada del G8 para promoverse como el nuevo gobierno de la economía mundial, dejando marginada a una gran parte de la humanidad, la que es más pobre" (EL G20..., 2009). ${ }^{8}$

Así la tan mentada democratización propuesta a partir de la ampliación del grupo a veinte miembros, resulta irrisoria, ya que silencia al resto del mundo: únicamente los estados miembro son capaces de gestionar la crisis financiera. Un interrogante que formulamos es porque no se avanza en consolidar el G192, es decir incluir en la discusión al conjunto de países que conforman las Naciones Unidas. Tal convocatoria realizada por la Presidencia de la Asamblea en Junio 2009 no tuvo la repercusión de los sucesivos encuentros del cónclave citado por el G20.

Un debate recorre el G20. Europa, epicentro de la crisis en la coyuntura, sostiene la necesidad del ajuste para retomar competitividad y reencauzar el camino para la obtención de ganancias y el ciclo de acumulación para la dominación. Mientras que desde EEUU se reclama continuidad en el salvataje empresarial, con estímulos estatales, para sostener el nivel de actividad económica. Se nota un empate, ya que se viene acordando una reducción de los déficit fiscales hacia el 2013 y que cada quién sostenga los estímulos en cada país. Al final, se trata de soluciones nacionales (anárquicas) para problemas de índole mundial.

Incluso Paul Krugman, premio Nobel de Economía en 2008 en un reciente artículo advierte que asistimos a la tercera gran depresión en la historia del capitalismo: la "[... l larga depresión [...]" iniciada en 1874, la "[...] gran depresión [...]"” de 1930 y la actual, cuyo “[...] costo para la economía mundial y, sobre todo, para los millones de vidas azotadas por la falta de empleo será enorme. $Y$ esta tercera depresión será, primordialmente, un error de política" (KRUGMAN, 2010). Los dirigentes del G20 parecen no sintonizar en ese sentido, mientras la crisis profundiza el desempleo y la pobreza en la mayoría de la población mundial.

En contraposición a lo planteado, prosiguen las reuniones paralelas del movimiento popular regional y mundial, las cuales deben de-

${ }^{8}$ Comunicado de ATTAC Francia (EL G20..., 2009). 
finir un proyecto alternativo al capitalismo, tomando la crisis como oportunidad. Los movimientos sociales pretenden participar en el debate a fin de que no se reincida en promover un formato de arquitectura financiera propio del ciclo anterior. Es la discusión por una Nueva Arquitectura Financiera del orden regional e internacional, que brega por la redefinición del ¿para qué? y ¿para quién? del financiamiento.

El Banco del Sur y el Banco del Alianza Bolivariana para los Pueblos de Nuestra América (ALBA) son respuestas originales a la crisis. Ambas instituciones, según lo expresan sus estatutos fundacionales, apuntan al financiamiento para el desarrollo y a la eliminación de las asimetrías regionales.

Otro desarrollo alternativo es el Sistema de Pagos en Monedas Locales (SML) entre Brasil y Argentina, que favorece la compensación con monedas locales del comercio bilateral, deteriorado por la crisis iniciada en 2007. Por medio del SML, los exportadores e importadores cobran y pagan en moneda local a través de los bancos adheridos al sistema. Es un régimen voluntario que pretende extenderse al conjunto de los países miembros del MERCOSUR. Este sistema de compensación puede ser comparable con el Sistema Único de Compensación Regional (S.U.C.RE). El ejemplo es útil para evidenciar las tendencias contradictorias que coexisten en la actualidad. El G20 trabaja en pos de restablecer el orden global, mientras que otras experiencias pueden avanzar en un sentido alternativo.

\section{8 ¿PUNTO DE INFLEXIÓN POLÍTICA? ¿RETORNOS DE LAS DERECHAS?}

En el marco de los horizontes posibles para salir de la crisis en Latinoamérica se plantea un debate coyuntural en el plano político referido a la existencia o no de un punto de inflexión en la política regional a raíz de la elección de Sebastián Piñera en Chile. La discusión no es menor en este contexto dado que la conclusión a la cual se arribe puede determinar el rumbo propuesto para la salida de la crisis. 
Con el resultado electoral en Chile en enero de 2010, se difundió el interrogante acerca de si existe un punto de inflexión en la tendencia política que se presentaba en la última década en América Latina y el Caribe. Sin embargo, y para ser ecuánimes, no debemos soslayar la existencia de un hecho simultáneo como lo es la asunción en el gobierno de Bolivia, del dúo Evo Morales y Álvaro García Linera por un segundo periodo. No deja de ser un interrogante saber porqué pesa más en algunas reflexiones la impronta que asume el millonario pinochetista, que la renovación con aires de radicalización que imponen los vecinos del altiplano, con un enunciado por el socialismo comunitario.

En todo caso, el interrogante es sobre que pesa más en el debate político e ideológico regional, en el clima de época, si el capitalismo exacerbado del derechista chileno, o la opción socialista del gobierno boliviano.

Si hay punto de inflexión es que la tendencia se modifica. ¿Hay o habrá cambio de rumbo? ¿Hay o habrá restauración conservadora? Para responder los interrogantes hay que trasladarse en el tiempo y pensar en periodos más largos, precisamente el que determina el origen de las políticas hegemónicas de las últimas cuatro décadas. Es en Chile con el golpe genocida de 1973 que se hace manifiesta la gigantesca ofensiva del capital sobre el trabajo, la sociedad y la naturaleza. Quiero enfatizar que la inflexión fue el golpe pinochetista, pues la tendencia de aquellos tiempos era favorable a la necesaria construcción de otro sistema internacional de relaciones sociales. El mundo era bipolar y con contradicciones se manifestaba una fortísima acumulación de poder popular con el imaginario socialista, las luchas de los trabajadores y los pueblos que estaban en las movilizaciones de los 60' y 70', en el triunfo del pueblo vietnamita y en la caída de la tasa de ganancia del capital ante el gigantesco nivel de resistencia y organización de los trabajadores en los países capitalistas de todo el mundo. Desde ese punto de apoyo y amparado en el Terrorismo de Estado, la tendencia global mutó hacia las políticas reaccionarias hegemónicas de los 90', donde las ideas de la escuela de Chicago se impusieron.

Es un proceso potenciado con la caída del este de Europa y la obstaculización en la subjetividad popular para pensar en la posibilidad 
socialista. El mundo se hizo capitalista por excelencia en los 90', al punto de habilitar teorizaciones como las del fin de la historia.

La resistencia a la iniciativa política del capital (neoliberalismo) construyó la expectativa latinoamericana del primer decenio del Siglo XXI y habilitó hace apenas un lustro la reivindicación del socialismo como propuesta de solución para los problemas de los pueblos. Primero en Venezuela se habló de socialismo del siglo XXI y ahora en Bolivia de socialismo comunitario. Convengamos que ello se explica en buena medida por el medio siglo de la experiencia socialista en Cuba. El caso es que los tres países protagonizan junto a otros una interesante y desafiante experiencia de integración, la Alianza Bolivariana para los Pueblos de Nuestra América (ALBA). Son estos los protagonistas destacados de la Cumbre de Copenhague (Diciembre del 2009) que no reclamaron un lugar en el productivismo capitalista, sino que identificaron como responsable de la crisis climática al capitalismo. Más allá de los adjetivos (del siglo XXI ó comunitario) con que se califiquen los rumbos sociales definidos, el socialismo vuelve a la agenda de la región y del mundo de la mano de los que hacen el ALBA.

Si la realidad es la crisis de la economía mundial y la respuesta que explica la recuperación económica de los principales países capitalistas se sustenta en cifras alarmantes de desempleo, empobrecimiento y hambre en todo el planeta, nos queda claro que la salida capitalista de la crisis se sustenta en mayor explotación de la fuerza de trabajo mundial.

La inflexión empezó con la visible acción colectiva de los pueblos que construyen, con limitaciones enormes, la práctica del otro mundo posible. ¿Es una realidad irreversible? La caída del socialismo real nos enseña que no existe irreversibilidad, que la lucha de clases existe más allá de la voluntad y que vencer la ofensiva capitalista lanzada en la crisis de los 70' requiere mucho más que voluntad o discurso de transformación social. Para ello se necesita potenciar sujetos conscientes que luchen por dar una salida anticapitalista a la crisis de la economía mundial en nuestro tiempo. En esta definición radican los límites de proyectos políticos que al no proponerse la superación del capitalismo, condenan sus intentos transformadores (en el caso que los hubiera) a la lógica del régimen del capital 
en tiempo de transnacionalización. En todos los países de la región en que se generó expectativa de cambios progresistas se discutió y discute como asegurar una herencia política transformadora en el plano institucional.

En síntesis, no hay inflexión hacia la derecha en la región con el triunfo de Piñera, aunque si es obvio que triunfó en los comicios el proyecto explícito de la derecha política chilena. Es bueno interrogarse y profundizar en las causas que motivaron ese resultado e incluso en el carácter de los gobiernos de la concertación. Ello no supone pensar en construcciones de socialismo mágico, de la noche a la mañana. Como dice Álvaro García Linera, la perspectiva puede llevar años ó siglos. Pero lo que no puede hacerse es escamotear la perspectiva anticapitalista y por el socialismo. Es una cuestión más allá de la disputa institucional y se asocia al poder popular.

La inflexión viene por la reinstalación de la crítica al capitalismo y la formulación del objetivo socialista. No es un rumbo irreversible y menos mayoritario, pero es una realidad.

\section{ORGANIZAR LA SUBJETIVIDAD PARA DISPUTAR PODER POPULAR}

En este marco de crisis estructural, apuntamos a señalar la coexistencia de dos escenarios. De un lado, el coordinado accionar entre las empresas transnacionales y los Estados nacionales capitalistas en el G20 - incluyendo los de América Latina: México, Brasil y Argentina - en pos de reconstruir el orden mundial liberalizador. Del otro de ubican los pueblos, principales perjudicados de las políticas regresivas inmanentes a ese orden socioeconómico. Su desconcierto ante la crisis, no les impide avanzar, aunque desorganizados y fragmentados, hacia las iniciativas políticas más audaces para transformar la realidad. Pero aun así: ¿cuánto participan los movimientos populares en el Banco del ALBA, o en el ALBA como proyecto integral de liberación? Son interrogantes para considerar críticamente los nuevos instrumentos que la práctica política transformadora está gestando. 
Los pueblos son los que tienen que impulsar las iniciativas. América Latina y el Caribe tienen más de 500 mil millones de dólares en reservas internacionales. ¿Se continuará financiando al capitalismo en crisis? ¿Se pueden aplicar a destinos soberanos? ¿Cuántas reservas internacionales hacen falta para que un país como Argentina, Bolivia, Brasil, Paraguay no sea objeto de una especulación financiera? ¿No es tiempo de pensar en mecanismos de uso compartido de esos recursos? ¿Esos fondos se mantendrán invertidos en bonos del Tesoro de Estados unidos ó prestándole al FMI? Son interrogantes para discutir una aplicación creativa destinada a satisfacer necesidades sociales irresueltas en nuestros países. Es probable que ello nos conduzca a otros interrogantes analizados. ¿No será que hay que discutir capitalismo como sistema ordenador de nuestra sociedad? ¿Pensar en medidas anticapitalistas tendientes a crear un orden poscapitalista?

América Latina y el Caribe tienen todas las condiciones. Y que quede claro que no estamos proponiendo el aislamiento de América Latina, sino incitando a propiciar un mayor vínculo con África, Asia y con los pueblos pobres del norte. Porque a partir de la iniciativa diversa, creativa y alternativa de los pueblos, se erige el poder popular, es decir el ejercicio legitimo de la autodeterminación de los pueblos.

En este inicio del siglo XXI resulta fácil el pesimismo sobre las perspectivas futuras de un socialismo de poder social; pero es importante recordar que en todo el mundo se están ensayando muchas de esas propuestas. Existen experimentos, se están construyendo continuamente nuevas instituciones ( $y$ también, desgraciadamente, destruyendo) en los intersticios de las sociedades capitalistas, y de vez en cuando se producen victorias políticas en las que el Estado puede colaborar en el proceso de innovación social. Constantemente surgen nuevas formas de poder social. No sabemos cuáles puedan ser los límites de tales experimentos parciales y fragmentarios y de la innovación en el capitalismo: el poder social puede quedar en último término restringido a los márgenes, o puede haber mucha más capacidad de maniobra. Pero lo que es seguro es que todavía no hemos llegado a esos límites (WRIGTH, 2006, p. 109). 
Está claro que el tema queda abierto a la riqueza inconmensurable de la creatividad social.

\section{REFERÊNCIAS}

EL G20, tres veces cero y nuevas gesticulaciones en vano: comunicado de ATTAC Francia. 28 sep. 2009. Disponible en: <http://www. attacmallorca.es/2009/09/27/el-g20-tres-veces-cero-y-nuevas-gesticulaciones-en-vano/>.

KRUGMAN, P. Al rescate de los incompetentes. Diario Clarín, Buenos Aires, 3 feb. 2009.

. El mundo ante la tercera depresión. Diario La Nación, Buenos Aires, 29 jun. 2010. Disponible en: <http://www.lanacion.com. ar/1279833-el-mundo-ante-la-tercera-depresion>.

LEADERS' STATEMENT THE PITTSBURGH SUMMIT SEPTEMBER 24-25 2009. Sep. 2009. Disponible en: <http://www.g20.org/Documents/pittsburgh_summit_leaders_statement_250909.pdf $>$.

MARIÁTEGUI, J. C. Obras. El Vedado - La Habana: Casa de las Américas, mar. 1982. Tomos I y II.

MARTINEZ GARCIA, Carlos. El G20 no puede dar más de sí: entendemos que tampoco lo pretende. 29 sep. 2009. Disponible en: <http://www.attacmallorca.es/2009/09/29/el-g-20-no-puede-dar-mas-de-si-entendemos-que-tampoco-lo-pretende/>.

SACHS, J. Está naciendo un nuevo capitalismo. Diario Clarín, Buenos Aires, 14 feb. 2009.

THE G-20 TORONTO SUMMIT DECLARATION june 26-27, 2010. Jun.2010. Disponible en: <http://www.g20.org/Documents/g20_declaration_en.pdf $>$.

WRIGTH, E. O. Los puntos de la brújula: hacia una alternativa socialista. New Left Review, Madrid, n. 41, p. 109, nov./dic. 2006. 